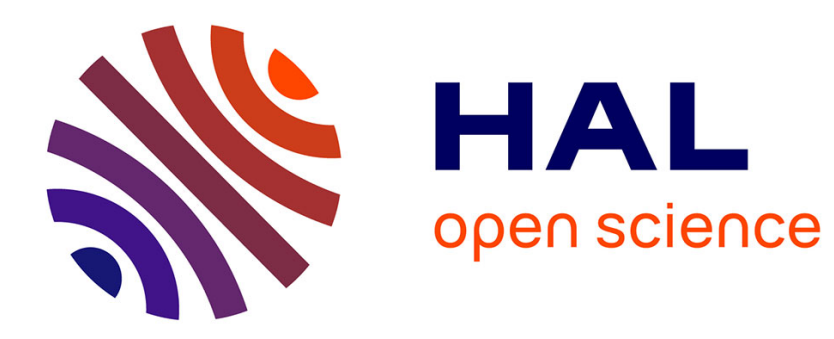

\title{
Le cycle mitotique chez les plantes : revue bibliographique \\ Monique Delbos
}

\section{To cite this version:}

Monique Delbos. Le cycle mitotique chez les plantes: revue bibliographique. Agronomie, 1983, 3 (6), pp.595-605. hal-00884548

\section{HAL Id: hal-00884548 \\ https://hal.science/hal-00884548}

Submitted on 1 Jan 1983

HAL is a multi-disciplinary open access archive for the deposit and dissemination of scientific research documents, whether they are published or not. The documents may come from teaching and research institutions in France or abroad, or from public or private research centers.
L'archive ouverte pluridisciplinaire HAL, est destinée au dépôt et à la diffusion de documents scientifiques de niveau recherche, publiés ou non, émanant des établissements d'enseignement et de recherche français ou étrangers, des laboratoires publics ou privés. 


\title{
Le cycle mitotique chez les plantes : revue bibliographique
}

\author{
Monique DELBOS \\ Institut de Biocénotique Expérimentale des Agrosystèmes (I.B.E.A.S.), Université de Pau et des Pays de \\ l'Adour, Casino, Municipal - Parc Beaumont, F 64000 Pau
}

RÉSUMÉ

\begin{abstract}
La durée du cycle mitotique est caractéristique d'une variété donnée, sinon d'une espèce. Ceci n'exclut pas les effets de facteurs externes à la plante comme le rythme circadien, la température, l'action de substances variées, les irradiations et certains effets intrinsèques (stade de développement de la plante, nature des tissus employés).

Après la mise en évidence de la relation entre teneur en ADN et durée du cycle, puis celle de la composition de l'ADN et la structure des chromosomes, on peut espérer mettre en évidence la relation banding-cycle mitotique.
\end{abstract}

Mots clés additionnels : Phases $G_{l}, S, G_{2}$, Mitose, ADN, Chromosome, Chromatine.

The duration of the mitotic cycle is characteristic of a given variety, if not of a species. However, this does not exclude the effects of external factors (circadian rythm, temperature, action of various substances, irradiation) and intrinsic effects (stage of development of the plant, nature of tissues used).

After first demonstrating the relation between the amount of DNA and the duration of the cycle, then the relation between DNA composition and chromosome structure, we may hope to establish a banding-mitotic cycle relationship.

Additional key words : $G_{1}, S, G_{2}$ phases, Mitosis, DNA, Chromosome, Chromatin.

\section{INTRODUCTION}

Avec la progression des techniques cytologiques (cytophotométrie, autoradiographie), la connaissance de l'évolution des cellules méristématiques s'est considérablement enrichic. D'autre part, les techniques plus récentes du banding permettent de faire apparaître des structures chromosomiques jusque-là masquées. Enfin la biochimie a enrichi la connaissance de l'ADN et de la chromatine.

\section{PRESENTATION DU CYCLE MITOTIQUE}

Le cycle mitotique peut être défini comme la succession des événements relatifs à la division cellulaire qui surviennent dans une cellule méristématique.

En 1953, HowARD \& PELC ont mis en évidence que la réplication de l'ADN et des chromosomes avait lieu au milieu de l'interphase. Cette phase $S$, phase de réplication de l'ADN, est située entre 2 intervalles (gap en anglais), d'où 'les abréviations $G_{1}$ et $G_{2} \cdot G_{1}$ précède la réplication et $\mathrm{G}_{2}$ la suit.
QUASTLER \& SHERMAN (1959), grâce à l'emploi d'isotopes radioactifs (thymidine tritiée) pendant un court laps de temps, obtiennent une courbe dite PLM (Percentage of Labelled Mitosis) qui permet de déterminer les durées du cycle total et des phases $\mathrm{tG}_{2}$, $\mathrm{tS}$, et $\mathrm{tM}+\mathrm{tG}_{1}$. La détermination de $\mathrm{tM}$ (et de $\mathrm{tG}_{1}$ ) à partir de ces seuls éléments suppose l'introduction d'une hypothèse concernant la répartition des pourcentages des différentes phases.

LAJTHA (1963) a noté l'arrêt prolongé de certaines cellules en $G_{1}$. Il en a tiré le concept de $G_{O}$, également applicable à la phase $G_{2}$ (GELFANT, 1963), et peut donc caractériser soit $G_{\mathrm{O} 2 \mathrm{C}}$, soit $\mathrm{G}_{\mathrm{O} 4 \mathrm{C}}$, selon la teneur en $A D N$ des noyaux ( $2 \mathrm{C}$ avant la phase $\mathrm{S}, 4 \mathrm{C}$ après pour un organisme diploïde). Il y a un échange permanent entre les populations $G_{1}$ et $G_{O 2 C}$. Cet échange se réaliserait avec une certaine probabilité $\mathrm{P}$, dite probabilité de transition (SMITH \& MARTIN, 1973).

Il existe un point d'arrêt $\mathbf{R}$ qui contrôle le passage des cellules de $\mathrm{G}_{1}$ en $\mathrm{S}$ (MAZIA, 1961 ; ZEUTHEN, 1964 ; MitCHINSON, 1971 ; VAN'T HoF \& KovaCs, 1972 ; PARDEE, 1974; ESSAD, 1978). Ce passage est soumis à l'influence de la plupart des facteurs d'inhibition naturels (nutrition, facteurs physiques et chimiques notamment). 


\section{FACTEURS AGISSANT SUR LE CYCLE MITOTIQUE}

Le cycle mitotique est le produit de l'interaction d'un grand nombre de systèmes régulés, qui sont couplés les uns aux autres. Nous pouvons classer ces facteurs en 2 grands groupes: externe et interne. Le tableau 1, donnant les durées des différentes phases du cycle pour différentes espèces, dans différentes conditions, va nous permettre de vérifier ces points. Nous devons compléter cette étude par des exemples autres que les plantes supérieures.

TABLEAU 1

Revue bibliographique des teneurs en $A D N$ et des durées du cycle mitotique chez diverses plantes. Bibliographical review of DNA amounts and duration of mitotic cycle in different plants.

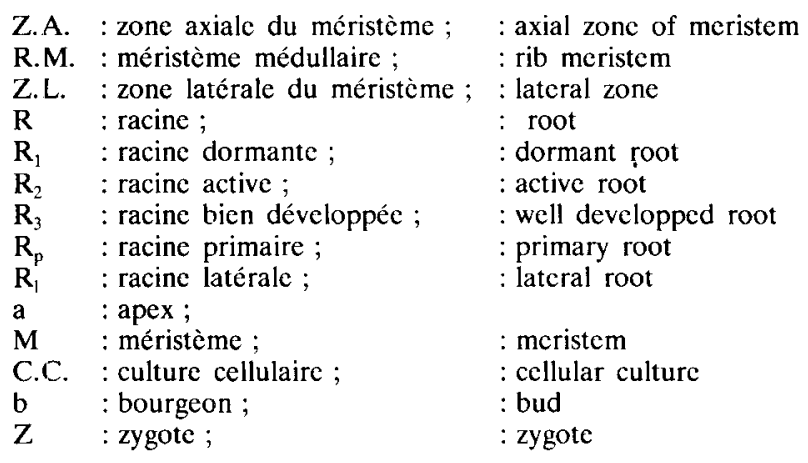

\begin{tabular}{|c|c|c|c|c|c|c|c|c|c|}
\hline Espèce & Organe & $\mathrm{T}^{\mathrm{o}}$ & ADN & $\mathrm{CT}$ & $\mathrm{tG}_{1}$ & $\mathrm{tS}$ & $\mathrm{tG}_{2}$ & $\mathrm{tM}$ & Référence \\
\hline \multicolumn{10}{|l|}{ I. Monocotylédones } \\
\hline var. Excellence & $\mathrm{R}$ & 23 & 54,3 & 17,4 & - & 10,9 & - & - & VAN'T HOF, 1965 \\
\hline \multirow[t]{2}{*}{ var. Eva Bunch } & & & & 12,8 & 1,5 & 6,5 & 2,4 & 2,3 & BRYANT, 1969 \\
\hline & & & 33,5 & 17,8 & 0,5 & 9,6 & & & Evans \& ReEs, 1971 \\
\hline \multirow[t]{2}{*}{ Allium fistulosum } & $\mathbf{R}$ & 23 & 41,0 & 18,8 & - & 10,3 & - & - & VAN'T HOF, 1965 \\
\hline & & & 26,3 & 15,3 & 0,5 & 9,6 & & & Evans \& REES, 1971 \\
\hline A. cepa $\times$ A. fistulosum & & & 29,9 & 16,6 & & 8,6 & & & EVANS \& REES, 1971 \\
\hline Allium tuberosum & & 23 & 66,3 & 20,6 & - & 11,8 & - & - & VAN'T HOF, 1965 \\
\hline \multicolumn{10}{|l|}{ Avena strigosa } \\
\hline $2 x$ & & 25 & & 9,8 & 2,45 & 3,55 & 2,0 & 1,8 & YANG \& DODSON, 1970 \\
\hline $4 \times$ & & 25 & & 9,9 & 1,0 & 3,75 & 3,55 & 1,6 & YANG \& DODSON, 1970 \\
\hline \multirow{3}{*}{$\begin{array}{l}\text { Bellevalia romana } \\
\text { Hordeum sativum }\end{array}$} & & & \multirow[b]{2}{*}{20,0} & 21,0 & 6,0 & 7,0 & 5,2 & 2,7 & JONA, 1966 \\
\hline & & & & & & & & & BENNETT \& SMITH, 1971 \\
\hline & & & & 12,0 & 2,6 & 4,9 & 3,4 & 1,1 & SARMA, 1971 \\
\hline Hordeum vulgare & & & $19,6-20,3$ & & & & & & BENNETT, 1972 \\
\hline var. Sultan (printemps) & & & & 12,4 & 2,55 & 3,8 & 4,3 & 1,75 & BENNETT \& FINCH, 1972 \\
\hline var. Maris otter (hiver) & & & & 12,0 & 1,8 & 3,5 & 5,0 & 1,7 & BENNETT \& FINCH, 1972 \\
\hline \multicolumn{10}{|l|}{ Hyacinthus orientalis } \\
\hline $2 \mathrm{x}$ & & & 49,7 & 24,0 & 0,8 & 13,6 & & & EVANS et al., 1972 \\
\hline $3 x$ & & & 73,7 & 27,0 & & & & & EVANs et al., 1972 \\
\hline $4 x$ & & & 94,2 & 30,2 & & & & & Evans et al., 1972 \\
\hline \multicolumn{10}{|l|}{ Lolium perenne } \\
\hline (0 B) & & & & 9,9 & 8,6 & 0,5 & 4,2 & & EVANS \& REES, 1971 \\
\hline (3 B) & & & & 12,0 & 10,0 & & 5,5 & & Evans \& RFEs, 1971 \\
\hline Secale cereale & & & 18,0 & & & & & & VANT HOF, 1974 \\
\hline $2 \mathrm{x}$ & & & 18,9 & 11,7 & 1,0 & 6,0 & & & EVANs et al., 1972 \\
\hline $4 x$ & & & 37,8 & 14,5 & & 7,4 & & & Evans et al., 1972 \\
\hline $0 \mathrm{~B}$ & & & 18,9 & 11,7 & & 6,0 & & & EVANS et al., 1972 \\
\hline $1 \mathrm{~B}$ & & & 20,2 & 13,1 & & 6,9 & & & EVANs et al., 1972 \\
\hline $2 \mathrm{~B}$ & & & 21,5 & 15,0 & & 7,6 & & & EVANs et al., 1972 \\
\hline $3 \mathrm{~B}$ & & & 22,8 & 14,0 & & 7,1 & & & Evans el al., 1972 \\
\hline $4 \mathrm{~B}$ & & & 24,1 & 17,1 & & 9,1 & & & Evans et al., 1972 \\
\hline Tradescantia paludosa & & & 59,4 & & & & & & SparRow \& MiKSHI:, 1961 \\
\hline \multirow[t]{6}{*}{$\mathrm{B}_{2}-2$ Sparrow's clone } & $\mathrm{R}_{1}$ & & & 19,4 & 4,4 & 11,4 & 1,6 & 2,0 & VAN'T HOF \& SPARROW, 1965 \\
\hline & $\mathbf{R}_{2}$ & & & 20,5 & 5,3 & 10,1 & 2,6 & 2,0 & VAN'T HOF \& SPARROW, 1965 \\
\hline & $\mathbf{R}_{3}$ & 22 & & 20,0 & 4,0 & 10,8 & 2,7 & 2,5 & WIMBER, 1960 \\
\hline & & 30 & & 16,0 & 2,4 & 9,5 & 2,4 & 1,7 & WIMBER, 1966 \\
\hline & & 21 & & 20,8 & 5,8 & 10,8 & 2,5 & 1,7 & WiMBER, 1966 \\
\hline & & 13 & & 51,0 & 15,4 & 22,5 & 8,3 & 5,0 & WIMBER, 1966 \\
\hline \multicolumn{10}{|l|}{ Triticale } \\
\hline var. Ammadillo & & & & 11,0 & 2,8 & 5,25 & 2,5 & 0,5 & KALTSIKES, 1972 \\
\hline var. Rosner & & & & 12,0 & 2,4 & 6,25 & 3,1 & 0,45 & KALTSIKES, 1972 \\
\hline Triticum aestivum & & & 36,1 & & & & & & VAN'T HOF, 1974 \\
\hline $\begin{array}{l}\text { var. Etoile de Choisy } \\
\text { Triticum durum }\end{array}$ & $\mathbf{R}$ & 23 & & & & & 1,10 & 0,96 & ESSAD \& BOUSQUET, 1981 \\
\hline var. Aziziati & & 23 & & 14,0 & 2,2 & 6,3 & 4,2 & 1,0 & AvanzI \& DERI, 1969 \\
\hline var. Capelli & & & & 16,2 & 1,3 & 9,3 & 4,7 & 0,3 & AvANZI \& DERI, 1969 \\
\hline
\end{tabular}




\begin{tabular}{|c|c|c|c|c|c|c|c|c|c|}
\hline Espèce & Organe & $\mathrm{T}^{\mathrm{o}}$ & ADN & CT & $\mathbf{t G}_{1}$ & tS & $\mathbf{t G}_{2}$ & $\mathrm{t} M$ & Référence \\
\hline Zea mays & & & 15,5 & & & & & & MC LEISH \& SUNDERLAND, 1961 \\
\hline F 546 & $\mathbf{R}$ & 24 & & $\begin{array}{r}22,0 \\
8,7\end{array}$ & $\underline{2,0}$ & $\begin{array}{r}11,0 \\
3,8\end{array}$ & $\begin{array}{l}7,0 \\
3,55\end{array}$ & $\begin{array}{l}2,0 \\
2,4\end{array}$ & $\begin{array}{l}\text { Clowes, } 1965 \\
\text { ESSAD \& MAUNOURY, } 1979\end{array}$ \\
\hline W $64 \mathrm{~A}$ & & & & $\begin{array}{r}0,1 \\
11,8\end{array}$ & 1,5 & 3,7 & 3,99 & 2,6 & ESSAD \& MAUNOURY, 1979 \\
\hline I.N.R.A. 508 (hybride) & & & & 9,3 & 0,2 & 3,3 & 3,7 & 2,0 & EsSAD \& Maunoury, 1979 \\
\hline $2 \mathrm{x}$ & & & 11,0 & 10,5 & 0,5 & 4,25 & & & EvANS et al., 1972 \\
\hline $4 x$ & & & 22,0 & 13,0 & & 7,4 & & & EVANS et al., 1972 \\
\hline $0 \mathrm{~B}$ & & & 11,0 & 10,5 & & 4,25 & & & EVANS et al., 1972 \\
\hline $8 \mathrm{~B}$ & & & 15,0 & 13,5 & & 5,6 & & & EVANS et al., 1972 \\
\hline \multicolumn{10}{|l|}{ II. Dicotylédones } \\
\hline Arabidopsis thaliana & & 22 & 0,54 & 8,5 & 1,7 & 2,8 & $4^{*}$ & & $\begin{array}{l}\text { VANT HOF et al., } 1978\left(* \mathrm{tG}_{2}+\mathrm{tM} / 2\right) \\
\text { BENNETT, } 1972\end{array}$ \\
\hline Crepis capillaris & & & 4,2 & & & & & & EVANS \& REES, 1971 \\
\hline Chrysanthemum morifolium & $\mathbf{a}$ & & 3,8 & $\begin{array}{c}10,7 \\
7 \text { à } 73\end{array}$ & - & 3,2 & - & & $\begin{array}{l}\text { VAN'T HOF, } 1965 \\
\text { BERG, } 1966\end{array}$ \\
\hline \multirow[t]{2}{*}{ Chrysanthemum segetum } & Z.L. & & & 48,3 & & 7,9 & & 3,3 & \\
\hline & $\begin{array}{l}\text { Z.A. } \\
\text { R.M. }\end{array}$ & & & $\begin{array}{r}138,7 \\
70,3\end{array}$ & & $\begin{array}{r}10,1 \\
8,9\end{array}$ & & $\begin{array}{l}3,3 \\
2,9\end{array}$ & Nougarede \& Rembur, 1978 \\
\hline \multirow[t]{2}{*}{ Coleus blumei } & Z.L. & & & $130-150$ & & 8,9 & & & JACQMARD, 1970 \\
\hline & & & & 125 & & & & $7,6-9,5$ & SAINT Come, 1973 \\
\hline Datura stramonium & Z.L. & & & 36 & & & & $1,9-2,2$ & CORSON, 1969 \\
\hline \multirow[t]{2}{*}{ Haplopappus gracilis } & M & & & 10,5 & 3,5 & 4,0 & 1,4 & 1,6 & SPARVOLI et al., 1966 \\
\hline & C.C. & - & 12,0 & 22,0 & 9,3 & 6,4 & 4,9 & 1,4 & ERICKSON, 1967 \\
\hline Helianthus annuus & & 23 & & 16,0 & 7,0 & 5,5 & 1,3 & 1,3 & $\begin{array}{l}\text { VAN'T HOF \& SPARROW, } 1963 \\
\text { VANT HOF, } 1967\end{array}$ \\
\hline Impatiens balsamina & & 23 & 5,1 & 8,8 & & 3,9 & & & VANT HOF, 1965 \\
\hline \multicolumn{10}{|l|}{ Lactuca sativa } \\
\hline var. Estelle & & 23 & & 10,0 & 1,7 & 4,9 & 1,9 & 1,5 & EsSAD, 1976 \\
\hline Lathyrus angulatus & & & 8,9 & 12,25 & 4,4 & 3,9 & & & Evans \& ReEs, 1971 \\
\hline Lathyrus articulatus & & & 12,4 & 14,25 & 3,9 & 4,8 & & & EvAns \& REEs, 1971 \\
\hline Lathyrus hirsutus & & & 20,1 & 18,0 & 7,8 & 5,0 & & & EVANS \& REES, 1971 \\
\hline Lathyrus tingitanus & & & 18,1 & 16,75 & 6,3 & 5,3 & & & Evans \& ReEs, 1971 \\
\hline Linum usitatissimum & & & 1,4 & 11,2 & & 4,1 & & & EVANS \& REES, 1971 \\
\hline Lycopersicon esculentum & & 23 & 8,4 & 10,6 & & 4,3 & & & VAN T HOF, 1965 \\
\hline Melandrium album & & 25 & & 15,5 & & & & & Choudhury, 1969 \\
\hline $\begin{array}{l}\text { Nicotiana plumbaginifolia } \\
\text { (pbg) }\end{array}$ & $\mathrm{R}$ & $\begin{array}{l}22 \\
22\end{array}$ & & $\begin{array}{l}13,0 \\
11,0\end{array}$ & & 6,5 & 2,0 & & $\begin{array}{l}\text { Collins, } 1968 \\
\text { GuPTA, } 1969\end{array}$ \\
\hline \multicolumn{10}{|l|}{ Nicotiana tabacum (tbc) } \\
\hline var. Red russian & $\mathbf{R}$ & 22 & & 12,5 & & 5,0 & 2,0 & & Collins, 1968 \\
\hline var. Wisconsin 38 & $\mathrm{~b}$ & $\begin{array}{l}20 \\
22\end{array}$ & & $\begin{array}{r}11,5 \\
9,0\end{array}$ & 1,4 & 5,0 & 3,4 & 1,7 & $\begin{array}{l}\text { DELBOS, } 1979 \\
\text { GuPTA, } 1969\end{array}$ \\
\hline$N . p b g \times N . t b c$ & $\mathbf{R}$ & 22 & & 12,0 & & 5,3 & 3,0 & & COLLINS, 1968 \\
\hline Nigella dasmascena & & & 21,1 & 16,5 & 1,5 & 10,5 & & & EVANS \& REES, 1971 \\
\hline \multirow{2}{*}{ Petunia $T 1 \mathrm{~h}$} & $\mathbf{R}$ & 20 & & 13,0 & & 4,4 & & & EsSA.D et al., 1975 \\
\hline & $\mathrm{z}$ & 20 & & 111,0 & 75,0 & 4,6 & 28,5 & 2,9 & ESSAD et al., 1975 \\
\hline Pisum sativum & & & 8,0 & & & & & & VAN'T HOF, 1974 \\
\hline var. Witham wonder & & & & 13,0 & 4,0 & 4,5 & 3,3 & 1,4 & VAN'T Hof, 1967 \\
\hline var. Alaska & & 20 & & 13,5 & 5,0 & 4,5 & 3,0 & 1,2 & VAN'T HoF, 1967 \\
\hline var. Weitor & & & & 14,0 & 5,0 & 4,5 & 3,0 & 1,2 & VAN'T HOF, 1967 \\
\hline var. Lincoln & Z.A. & & & 69 & & & & $1-1,5$ & LYNDON, 1970 \\
\hline- & Z.L. & & & $28-30$ & & & & $1-1,5$ & LYNDON, 1970 \\
\hline - & R.M. & & & 26 & & & & $1-1,5$ & LYNDON, 1970 \\
\hline var. Nain hâtif d'Annonay & & & & 49 & & & & & NOUGAREDE, 1976 \\
\hline - & & & & 31 & & & & & NOUGAREDE, 1976 \\
\hline - & & & & 43 & & & & & NOUGAREDE, 1976 \\
\hline var. Alaska & & 30 & & 10 & & & & & VANT HOF \& SPARROW, 1963 \\
\hline- & & 25 & & 10 & & & & & VANT HOF \& SPARROW, 1963 \\
\hline- & & 15 & & 22 & & & & & VANT HOF \& SPARROW, 1963 \\
\hline- & & 10 & & 34 & & & & & VAN"T HOF \& SPARROW, 1963 \\
\hline Rudbeckia bicolor & $\mathrm{R}$ & & & 30,5 & $6,8^{*}$ & 15,9 & $7,8^{*}$ & & JACQMARD, $1970(*+\mathrm{tM} / 2)$ \\
\hline Sinapis alba & Z.L. & & & 15,7 & & & & $0,7-1,1$ & BODSON, 1975 \\
\hline Trifolium repens & Z.L. & & & $69-87$ & & & & $1,2-1,6$ & DENNE, 1966 \\
\hline Vicia faba & & & 20,0 & & & & & & VANT HOF, 1974 \\
\hline Sutton Prol. Lgp. & & & 13,9 & 18,5 & 4,5 & 7,5 & 4,5 & 2,0 & Evans \& SAVAGE, 1963 \\
\hline - & & 10 & & 19,3 & 4,9 & 7,5 & 4,9 & 2,0 & Evans \& SCOTT, 1964 \\
\hline Fève de Séville & & 19 & & 18,0 & 5,3 & 6,0 & 5,2 & 1,5 & GRANT \& HESLOT, 1965 \\
\hline & $\mathbf{R}_{\mathrm{p}}$ & & 38,0 & 18,0 & 4,0 & 9,0 & 3,5 & 1,9 & VAN'T HoF, 1967 \\
\hline & $R_{1}^{p}$ & & & 14,0 & 2,3 & $6-6,5$ & $3-4$ & 2,0 & WEBSTER, 1967 \\
\hline & - & $21-22$ & & 14,0 & 2,5 & 6,2 & 3,3 & 2,0 & WEBSTER \& DAVIDSON, 1968 \\
\hline & - & & & 16,6 & 3,6 & 8,3 & 2,9 & 1,7 & MC LEOD, 1968 \\
\hline & $\mathbf{R}_{\mathrm{p}}$ & 20 & & 18,0 & 3,5 & 9,2 & 2,4 & 3,0 & MC LEOD, 1971 \\
\hline Vicia sativa & & & & & & & & & \\
\hline var. Septimane) & $\mathbf{R}_{\mathrm{p}}$ & $22-24$ & 5,9 & 11,0 & 2,03 & 3,20 & 5,11 & 0,65 & EsSAD, 1973 \\
\hline var. Septimane hiver & - & - & 5,9 & 11,0 & 0,34 & 3,40 & 6,35 & 0,71 & EsSAD, 1973 \\
\hline var. Myrto J & - & - & 6,43 & 11,0 & 1,65 & 3,90 & 4,63 & 0,82 & EsSA.D, 1973 \\
\hline var. Sylphie $\}_{\text {printemps }}$ & - & - & 6,85 & 14,0 & 2,43 & 4,70 & 5,91 & 0,96 & ESSA.D, 1973 \\
\hline var. VSI \}printemps & - & - & 6,17 & 15,0 & 4,49 & 5,40 & 3,25 & 1,86 & ESSA.D, 1973 \\
\hline
\end{tabular}




\section{A. Le cycle circadien}

Le cycle circadien, rythme biologique de période d'environ $24 \mathrm{~h}$, a pour synchroniseurs lumière, température, alimentation, etc... CHALlONER et al. (1981) ont mis en évidence sa relation avec la phase $S$ par 2 méthodes, l'une autoradiographique, l'autre biochimique. EHRET \& Trucco (1967) en ont établi un modèle au point de vue moléculaire.

\section{B. Les alternances lumière-obscurcité, et les alternances : sécheresse-humidité}

L'alternance lumière-obscurité, étudiée plus particulièrement par SPUDICH \& SAGER (1980) sur Chlamydomonas, ainsi que l'alternance humidité-sécheresse (RAQUIN, comm. pers.) sont des conditions très connues et utilisées par les cytologistes. Il est à noter que toute modification dans l'alternance perturbe le cycle, en premier lieu en augmentant les mitoses, puis en les diminuant (Evans \& SavaGE, 1959). On devrait donc reprendre l'étude de ces alternances sur les végétaux.

\section{La température}

Evans \& SAVAGE (1959), Murin (1966), Wimber (1966), Burholt \& VAN'T Hof (1971), MurIN \& KOLEKOVA $(1979,1980)$ ont montré que l'effet de la température sur les différentes phases du cycle mitotique est déterminant (cf. tabl. 1, Pisum sativum, Tradescantia paludosa, par ex.). De ces travaux, on peut conclure que l'augmentation de température réduit la durée totale du cycle mitotique.

\section{Les irradiations}

Les facteurs nucléaires affectant la radiosensibilité ont été mis en évidence (EVANS \& SPARROW, 1961 ; SPARROW \& EVANS, 1961). En 1963, VAN'T HOF \& SPARROW trouvent qu'une irradiation chronique n'a pas d'effet sur la durée minimum du cycle total. En 1965, CLOWES démontre une relation positive entre radiosensibilité et durée de $\mathrm{G}_{1}\left(\mathrm{tG}_{1}\right)$. En 1967, BAETCKE et al. font état des relations entre teneur en ADN, volume chromosomique et radiosensibilité. En 1979, DELBos met en évidence l'action des rayons $\gamma$ et surtout celle des modalités d'irradiation, sur les différentes phases du cycle mitotique.

\section{E. Les ions et les différentes substances agissant sur le cycle}

\section{Ions $\mathrm{Ca}^{++}, \mathrm{Mg}^{++}, \mathrm{Zn}^{++}$}

Ces ions jouent un rôle dans la mitose. Les ions $\mathrm{Ca}^{++}$ sont impliqués dans la régulation de l'actine et de la myosine (NACHMIAS \& ASCH, 1976) et dans la formation de microtubules (WEISENBERG, 1972). On sait que les microtubules, ainsi que la myosine et l'actine, ont une fonction déterminante dans la mitose (fuseau achromatique) et, par conséquent, dans le déroulement du cycle (SLUDER, 1979). Ces ions ont une importance comme régulateurs de croissance (BERRIDGE, 1976). Ils sont aussi nécessaires à l'initiation de la synthèse d'ADN (RIXON \& WHITFIELDS, 1976 ; BOYTON et al., 1976 ; SWIERIENGA et al., 1976) et sont en interaction avec les nucléotides cycliques (BERRIDGE, 1975a, 1975b). Les ions $\mathrm{Mg}^{++}$interviennent dans la polymérisation de la tubuline et la formation du fuseau; leur absence provoque le blocage en phase $G_{2}$. D'autre part, la synthèse des protéines et celle de l'ADN sont sensibles à un faible changement dans la teneur intracellulaire en $\mathrm{Mg}^{++}$. Par action d'agent chélatant des ions $\mathrm{Zn}^{++}$, FALCHUCK \& KRISHAN (1977) ont montré que ces ions avaient une action sur le précurseur de l'ARN ribosomal $35 \mathrm{~S}$. D'autres ions jouent également un rôle (STAMBROOK et al., 1975).

Tous ces travaux ayant été effectués sur des cellules animales, la biologie végétale devrait donc s'intéresser à ce problème, d'autant plus que l'effet des ions sur les plantes supérieures est par ailleurs bien étudié.

\section{Substances de croissance}

Les gibbérellines ont pour effet général de raccourcir la durée de la mitose (SvarinSKaYA \& GaVRILOVA, 1976). Les cytokinines, en particulier la kinétine, la déclenchent (SKOOG et al., 1965; SKOOG et al., 1967; SKOOG \& ARMSTRONG 1970 ; JouANNEAU, 1971, 1975). D'autre part, les cytokinines induisent la biosynthèse d'auxines dans les cultures de cals (SKOOG et al., 1967). Les auxines ont aussi une action stimulante sur la division cellulaire (DALESSANDRO, 1973 ; DAS et al., 1956 ; PATAU et al., 1957 ; SKOOG \& ARMSTRONG, 1970 ; WighTMAN \& SETTERFIELD, 1968 ; JOUANNEAU, 1971).

\section{Phytotoxines}

L'ochracine, phytotoxine de Septoria nodorum, intervient par un blocage partiel en $G_{1} / S$, un allongement de $G_{2}$ et de la mitose dans le cycle cellulaire de Triticum aestivum (ESSAD \& BOUSQUET, 1981).

\section{Préfixateurs}

Les préfixateurs utilisés en cytologie, bloquent les cellules en métaphase, en particulier la colchicine (DUSTIN et al., 1937 ; ILAN \& QUASTEL, 1966 ; WILSON \& FRIEDKIN, 1967). La 8-hydroxyquinoléine, agent chélatant, agirait au niveau des ions $\mathrm{Ca}^{++}, \mathrm{Mg}^{++}$et $\mathrm{Zn}^{++}$en bloquant la transcription de l'ADN en ARN et sans doute aussi la polymérisation de la tubuline.

\section{Les nucléotides cycliques}

Leur rôle régulateur a été proposé en 1973 par ABELL \& MONAHAN, notamment pour l'AMP ${ }_{\text {C }}$ par PRESCOTT (1976), ZEILIG et al. (1976), et pour le GMP $_{\mathrm{C}}$ par SEIFERT \& RudLAND (1974a, b), ZEILIG \& GOLDBERG (1977). Il a été mis en doute en 1977 par AMRHEIN.

\section{Blocage spécifique}

Certaines substances bloquent le cycle mitotique à une phase déterminée. Le blocage en $G_{1}$ est effectué, par exemple, avec l'actinomycine D, 5-azacytidine, chalone, cycloheximide, mytomycine, puromycine. Le blocage en $S$ est réalisé par l'hydroxyurée, 5-aminouracile, les inhibiteurs de synthèse d'ADN et diverses autres substances. Celui de $\mathrm{G}_{2}$ est obtenu par l'actinomycine $\mathrm{D}$, amphotéricine, chalone, cycloheximide, puromycine. Il faut noter que certains agents sont spécifiques aux animaux (chalone par exemple), d'autres aux végétaux (5-aminouracile) et que d'autres enfin sont universels (hydroxyurée). On peut, à ce sujet, se référer à LLYOD et al. (1982).

\section{F. Stade de développement de la plante et nature des tissus employés}

Les effets de ces 2 paramètres ont été démontrés par LYNDON (1970) sur Pisum, REMBUR \& NougAREDE (1973), NOUGAREDE \& REMBUR (1978) sur 
Chrysanthemum, ESSAD et al. (1975) sur Petunia. D'autre part, les apex présentent 3 zones : zone latérale, méristème médullaire et zone axiale, qui ont des cycles différents (Nougarede \& Rembur, 1978). Par ailleurs, on tend à considérer que les méristèmes radiculaires présentent 2 populations mitocycliques différentes : une population à cycle mitotique rapide, révélé par la courbe PLM, et une autre, à cycle mitotique lent (WEBSTER \& DAVIDSON 1968; Clowes, 1971; EVANS \& VAN'T HoF, 1975). Cependant d'autres auteurs n'en sont pas convaincus (ESSAD, 1976).

\section{G. Variation des profils mitotiques à l'intérieur d'une espèce}

De l'ensemble des données, il ressort une homogénéité des durées CT et tS à l'intérieur des espèces Hordeum vulgare (BENNETT \& FINCH, 1972), Avena strigosa (YANG \& Dodson, 1970), Pisum sativum (VAN'T HoF, 1967), Tradescantia paludosa (WIMBER, 1960 ; VANT HoF \& SPARRow, 1965) au moins pour les variétés étudiées. Par contre, une certaine différence entre 2 cultivars de Triticum durum a été établie par AVANZI \& DERI (1969). Cette différence peut être contestée en raison du manque de précision des courbes PLM présentées. De même, la différence mise en évidence par KALTSIKES (1972) entre 2 cultivars de Triticale ( « Rosner» et « Amadillo ») est peut-être attribuable à des adaptations géographique et climatique différentes de ces 2 cultivars. Il faut cependant constater l'existence de 3 situations différentes:

a) variation sensible des durées des 2 paramètres considérés généralement comme les caractéristiques essentielles tS et CT pour Allium cepa, Tradescantia paludosa et Zea mays ;

$b$ ) absence de variation de CT et variation considérable de tS chez Vicia faba;

c) différence sensible des durées chez Vicia sativa entre des variétés d'hiver et de printemps.

\section{RELATION ENTRE LES DURÉES DES DIFFÉRENTES PHASES}

Il est intéressant de noter l'évolution de la durée de la phase $\mathrm{S}(\mathrm{tS})$ dans les différentes espèces et les variations relatives avec $C T, \mathrm{tG}_{1}$ et $\mathrm{tG}_{2}$.

\section{A. Relation entre durée du cycle total (CT) et celle de la phase $S$ (tS)}

Dans la figure 1, on voit la confirmation de la régression de VAN'T HOF (1965), CT $=5,26+1,27 \mathrm{t} S$, avec des écarts sensibles pour certains groupes taxonomiques (Vicia faba, Pisum sativum, Tradescantia paludosa, Composées). ESSAD (1973) remarque que la différenciation de la relation CT-tS entre les groupes végétaux superpose apparemment 3 causes essentielles des variations possibles : espèces, variétés, milieux, mais qu'à ces causes, se superposent des facteurs de variations: l'un d'ordre général et qui interviendrait seul pour les Monocotylédones $\left(\mathrm{tG}_{1}\right.$ constant) et l'autre dépendant pour les Dicotylédones des groupes évolutifs considérés.

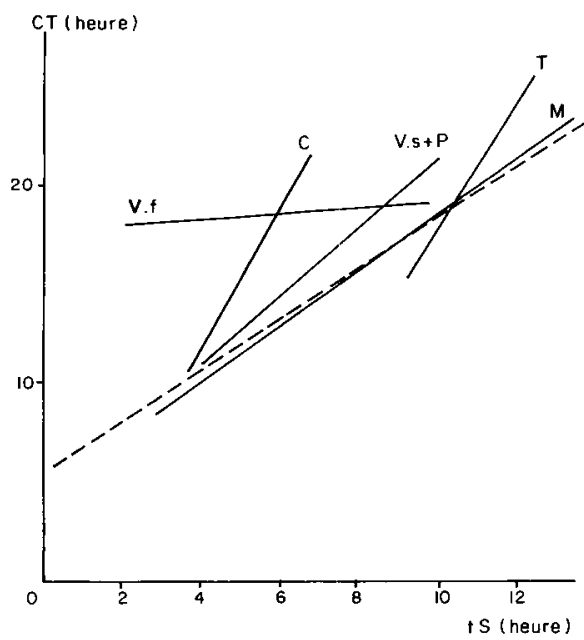

Figure 1

Relation statistique observée entre la durée du cycle total (CT) et celle de la phase $S(t S)$, d'après ESSAD (1973).

(- -) régression de VAN'T HOF (1965): $C T=5,26+1,27 t S$.

$C$ : Composées; $M$ : Monocotylédones; $T$ : Tradescantia ; Vf: Vicia faba $V s+P=V i c i a$ sativa et Pisum.

Statistical relationship between the duration of the total cycle (CT) and the duration of $S$ phase ( $t S)$, after ESSAD (1973).

(- - ) VANT HOF's regression (1965): $C T=5,26+1,27$ TS

$C$ : Composae ; $M$ : Monocotyledons ; $T$ : Tradescantia ; Vf: Vicia faba $; V s+P:$ Vicia sativa and Pisum.

\section{B. Relation entre durée de $G_{1}\left(t_{G_{1}}\right)$ et celle de la phase $S$} (tS)

La figure 2 montre un clivage entre Monocotylédones et Dicotylédones avec une valeur inférieure de $t G_{1}$ chez les Monocotylédones. Ce clivage a été déjà démontré par EVANS \& REES (1971) et par ESSAD (1973).

\section{Relation entre durée de $G_{2}\left(t_{G_{2}}\right)$ et celle de la phase $S$} (tS)

La figure 3 met en évidence un groupe à part, celui des Légumineuses, avec une séparation Vicia faba/Pisum sativum - Vicia sativa.

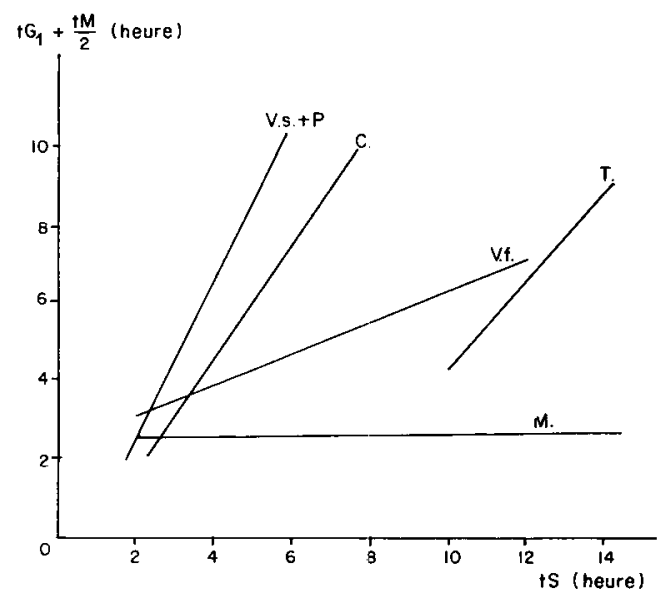

Figure 2

Relation observée entre la durée de la phase $S(t S)$ et celle de la phase $G_{1}$, augmentée de la moitié de la durée de la mitose $\left(t G_{1}+t M / 2\right)$, d'après ESSAD (1973). C, M, T, Vfet Vs $+P$ identiques à la fig. 1 . Relationship between the duration of $S$ phase $(t S)$ and the $G_{I}$ phase increased by half the duration of mitosis $\left(t G_{1}+t M / 2\right)$ after ESSAD (1973). C, $M, T, V f$ and $V s+P$ : same symbols as fig. 1 . 


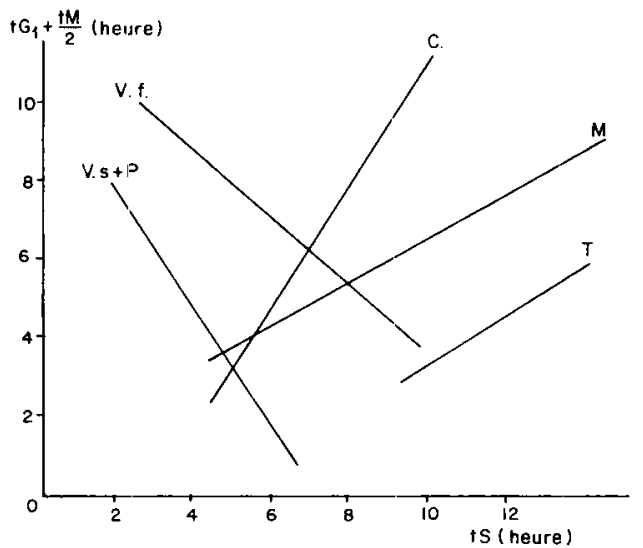

Figure 3

Relation entre la durée de la phase $S$ (tS) et celle de la phase $G_{2}$ augmentée de la moitié de la durée de la mitose $\left(t G_{2}+t M / 2\right)$, d'après ESSAD (1973). C, M, T, Vf et $V s+P$ identiques à la fig. 1 .

Relationship between the duration of $S$ phase $(t S)$ and the $G_{2}$, phase increased by half the duration of mitosis $\left(t G_{2}+t M / 2\right)$ after ESSAD (1973). C, M, T, Vf and Vs $+P$ : same symbols as fig. 1 .

\section{Conclusion}

Il existe une relation, non seulement entre $\mathbf{t} \mathrm{S}$ et $\mathrm{CT}$, à l'intérieur des groupes taxonomiques définis, mais aussi des interactions entre $\mathrm{t} S$ et $\mathrm{tG}_{1}$ ou $\mathrm{tG}_{2}$.

\section{RELATION ENTRE TENEUR EN ADN ET DURÉE DU CYCLE}

VAN'T Hof \& SPARRow (1963), VAN'T Hof (1965) ont montré la relation générale existant entre teneur en ADN et cycle mitotique. EVANS (1968), MIKSCHE (1968), NiSHIKAWA (1970) et ESSAD (1973) ont montré l'existence de différences intraspécifiques significatives concernant les teneurs en ADN. MIKSCHE \& ROLLINS (1971) et ESSAD (1973) ont mis en évidence l'absence de relation entre la durée de la phase $\mathrm{S}$ (tS) et la tencur en ADN chez Picea glauca et Vicia sativa. Cette relation varie selon qu'on a affaire à des diploïdes, des hybrides interspécifiques, des polyploïdes ou qu'il existe des chromosomes B.

\section{A. Chez les diploïdes}

BenNeTT (1972) a montré que :

1) les espèces annuelles ont une teneur en $\mathrm{ADN}$ plus faible en moyenne que les espèces pérennes;

2) l'amplitude de variation de la teneur en ADN nucléaire est plus faible chez les annuelles (maximum : $44 \mathrm{pg}$ ADN/noyau) que chez les pérennes (maximum : $295 \mathrm{pg}$ ) ;

3) les thérophytes ont une teneur en ADN plus faible que les phanérophytes ;

4) chez les Monocotylédones, la valeur moyenne d'ADN des pérennes obligatoires est significativement plus grande que celle des pérennes facultatives et les valeurs moyennes pour les pérennes facultatives et les annuelles ne sont pas significativement différentes. Cette variation de la teneur en ADN entraîne-t-elle une variation de la durée du cycle ?

\section{Cycle mitotique (fig. 4)}

VAN'T HOF (1965) trouve un taux d'accroissement de la durée du cycle total (CT) de $0,300 \mathrm{~h}$ par pg d'ADN

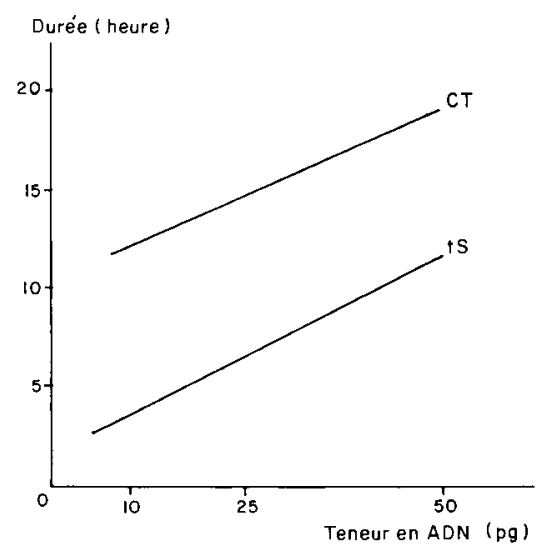

Figure 4

Relation statistique entre la teneur en $A D N$ par cellule et les durées du cycle total (CT) et de la phase $S$ ( $t S)$, d'après ESSAD (1973).

Relationship between DNA amount per cell and durations of total cycle (CT) and $S$ phase (tS) after ESSAD (1973).

supplémentaire. EvaNS et al. (1972) ont trouvé pour les Monocotylédones $0,374 \mathrm{~h} / \mathrm{pg}$ ADN et $0,385 \mathrm{~h} / \mathrm{pg}$ ADN pour les Dicotylédones. Ceci nous amène à étudier plus précisément cette séparation entre Monocotylédones et Dicotylédones.

\section{Monocotylédones et Dicotylédones}

Nous avons déjà vu ce clivage (fig. 1). Evans et al. (1972) ont montré que (fig. 5) :

1) la durée du cycle est plus longue de $4 \mathrm{~h}$ chez les Dicotylédones que chez les Monocotylédones pour une même teneur en ADN ;

2) il n'y a pas de différence au niveau de tS ;

3) mais cette différence se retrouve au niveau de $t G_{1}$.

\section{B. Hybridation interspécifique}

Les hybrides présentent une durée de cycles intermédiaire, directement liée à la teneur en ADN (cf. tabl. 1).

\section{Polyploïdie}

Les autopolyploïdes de maïs, seigle et jacinthe ont des durées de cycle mitotique et de phase $S$ plus longues que celles des diploïdes (EVANS et al., 1972). Il est clair aussi dans la figure 6 que les durées d'un cycle complet et de la phase $\mathrm{S}$ sont reliées à la teneur en $\mathrm{ADN}$, que leur taux

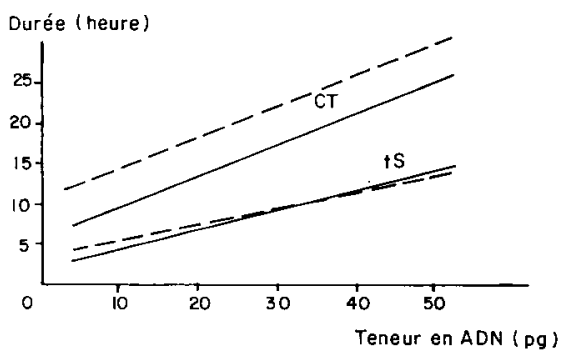

Figure 5

Relation entre la teneur en ADN par cellule et les durées du cycle total $(C T)$ et de la phase $S(t S)$ chez les Monocotylédones (-) et les Dicotylédones (---). (Evans et al., 1972).

Relationship between DNA amount per cell and durations of total cycle $(C T)$ and $S$ phase $(t S)$ in Monocotyledons ( - ) and Dicotyledons (--). (Evans et al., 1972). 


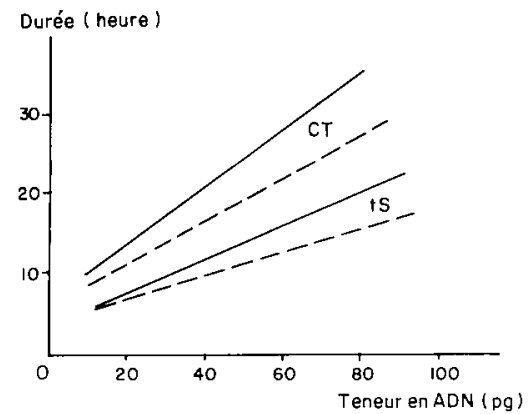

Figure 6

Relation entre la teneur en ADN par cellule et les durées du cycle total $(C T)$ et de la phase $S(t S)$ chez les diploïdes (-) et les polyploïdes (--). (EVANS ct al., 1972).

Relationship between DNA amount per cell and duration of total cycle $(C T)$ and $S$ phase $(I S)$ in diploids (-) and polyploids (--). (EVANS et al., 1972).

d'accroissement avec l'accroissement de l'ADN est plus faible chez les polyploïdes que chez les diploïdes ou même nul. Ceci est en forte contradiction avec ce qui a été observé chez d'autres autopolyploïdes (BAYLISS, 1975 ; FRIEDBERG \& DAVIDSON, 1970 ; TROY \& WIMBER, 1968 ; VAN'T HOF \& SPARROW, 1966 ; YANG \& DODSON, 1970) ainsi que chez quelques allopolyploïdes comme le blé hexaploïde chez lequel la durée du cycle mitotique est actuellement plus courte que celle de ses parents diploïdes (BENNETT, comm. pers. à EVANS, 1972).

\section{Chromosome B}

La figure 7 montre un taux d'accroissement de CT et tS disproportionnellement important par rapport à celui des diploïdes lors de l'addition de chromosomes B. Ce serait dû, selon Evans et al. (1972), soit à une réplication tardive du chromosome $\mathrm{B}$ liée à sa constitution hétérochromatique, soit au contrôle génotypique du chromosome B. Il est à noter que, selon KIRK \& JONES (1970), l'addition d'un chromosome B entraîne une augmentation de 4 p. 100 d'ADN, chez le seigle. Contrairement aux chromosomes B du seigle et du maïs qui sont, à un certain degré au moins,

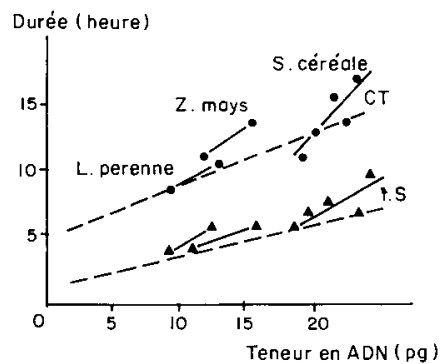

Figure 7

Effet des chromosomes sur la durée du cycle mitotique (CT) et de la synthèse $(t S)$ chez Zea mays, Lolium perenne et Secale cereale $(\mathrm{Z}$. mays, $O B$ et $8 B$; L. perenne, $O B$ et $3 B$; S. cereale $O B, I B, 2 B, 3 B$ et $4 B)$.

(- -) régression pour des Monocotylédones diploïdes (Evans et al., 1972).

Effect of B chromosomes on the duration of the mitotic cycle (CT) and synthesis $(t S)$ in Zea mays, Lolium perenne and Secale cereale (Z. mays, $O B$ and $8 B$; L. perenne, $O B$ and $8 B ; \mathrm{S}$. cereale, $O B, 1 B$, $2 B, 3 B$ and $4 B$ ).

(- - ) regression lines for diploid Monocotyledons (EVANS et al., 1972). hétérochromatiques et de réplication tardive, ceux de Lolium ne se répliquent pas tardivement. On ne peut donc expliquer complètement, par cette propriété, l'allongement de $S$ et CT pour une même teneur en ADN.

\section{E. Discussion}

La durée du cycle mitotique est fonction de la teneur en $\mathrm{ADN}$. Elle est sous contrôle génétique, étant donné qu'il existe des variations inter- et intraspécifiques. Au niveau moléculaire, les chromosomes ont plus d'un site d'initiation de réplication de l'ADN. Deux questions posées par EVANS et al. (1972) sont encore sans réponse :

1) un accroissement d'ADN chromosomique entraîne-t-il un changement dans la longueur ou le nombre de replicons par génome?

2) chez les hybrides, les chromosomes les plus longs devant compléter leur réplication plus vite et les plus courts plus lentement que chez les espèces parentales, y-a-t-il changement du nombre de replicons ou bien modification dans le taux de synthèse ?

Sachant que le cycle mitotique est en relation avec la teneur en ADN, on peut se demander s'il est aussi fonction de la composition de cet ADN. Aussi serait-il intéressant de savoir :

1) quelle fraction de l'ADN est variable ?

2) quelle est la relation entre fractions d'ADN et chromatine (eu- et hétérochromatine)?

3) l'hétérochromatine étant mise en évidence par le banding, peut-on établir une correspondance entre bandes des chromosomes, l'ADN et le cycle mitotique?

\section{RELATION ENTRE COMPOSITION DE L'ADN ET CHROMOSOMES}

De leurs travaux sur Lathyrus, NARAYAN \& REES (1976) ont conclu que :

1) l'augmentation d'ADN nucléaire est accompagnée d'une augmentation de la portion de l'ADN total constituée de séquences répétitives, en particulier de la fraction modérément répétitive. Ceci est conforme aux travaux de SMITH \& FlaVELl (1974) (fig. 8) ;

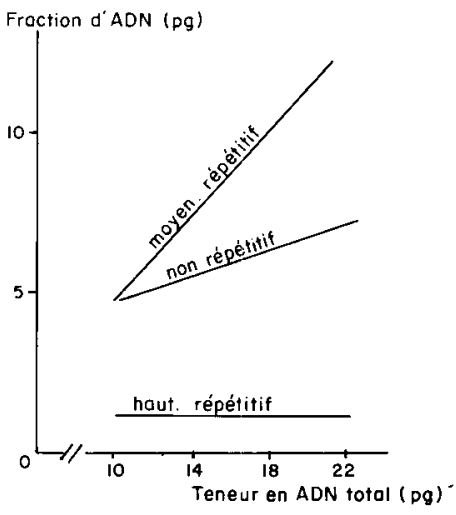

Figure 8

Relation entre la teneur en $A D N$ non répétitif, moyennement répétitif et hautement répétitif et la teneur en ADN total nucléaire (REES \& NARAYAN, 1977).

Amount of non-repetitive, and of moderately and highly repetitive DNA plotted against total DNA (REES \& NARAYAN, 1977). 
2) en termes cytologiques, l'augmentation d'ADN total correspond à un accroissement disproportionné en hétérochromatine ;

3) la variation entre espèces des proportions relatives de fractions répétitives ou non d'ADN chromosomique exclut la possibilité de changement quantitatif dû à une variation du nombre de brins d'ADN dans les chromosomes, c'est-àdire d'une polynémie différentielle.

En 1977, ces auteurs démontrent que la fraction non répétitive, de teneur constante, varie très peu dans sa composition.

REES \& NARAYAN (1977) ont montré qu'un changement de taille des chromosomes accompagne une variation quantitative du contenu nucléaire d'ADN, et en particulier :

1) un accroissement d'un pg d'ADN euchromatique s'accompagne d'un accroissement de 1,2 pg d'ADN hétérochromatique (fig. 9). Cette augmentation d'hétérochromatine se localise au voisinage des centromères;

2) un accroissement d'un pg d'ADN non répétitif s'accompagne d'une augmentation de $4 \mathrm{pg}$ d'ADN modérément répétitif ;

3) il y a peu de changement qualitatif dans l'ADN non répétitif qui contient les gènes structuraux.

Ils en concluent que, chez Lathyrus, chaque supplément d'ADN est un complexe de composition uniforme qui maintient les teneurs relatives en eu- et en hétérochromatine, et des séquences répétitives ou non d'ADN (fig. 8 et 9). Le modèle diffère seulement par les proportions relatives des fractions répétitives ou non. La question des fractions régulatrices de l'ADN supplémentaire est posée.

SHARMA $(1975,1978)$ a montré que les procédés de banding des chromosomes par le giemsa et l'orceine mettaient en évidence les segments hétérochromatiques, déjà reconnus par les procédés d'extraction, de dénaturation et réassociation d'ADN.

VoSA $(1973,1977)$ a noté que la teneur en hétérochromatine, riche en séquences répétitives, varie selon les espèces.

VERMA (1978), s'intéressant à la localisation proximale de l'hétérochromatine constitutive, a montré que :

1) les chromocentres à l'interphase correspondent aux bandes $\mathrm{C}$;

2) la condensation chromosomique de la fin de la prophase à la métaphase affecte toutes les régions de manière

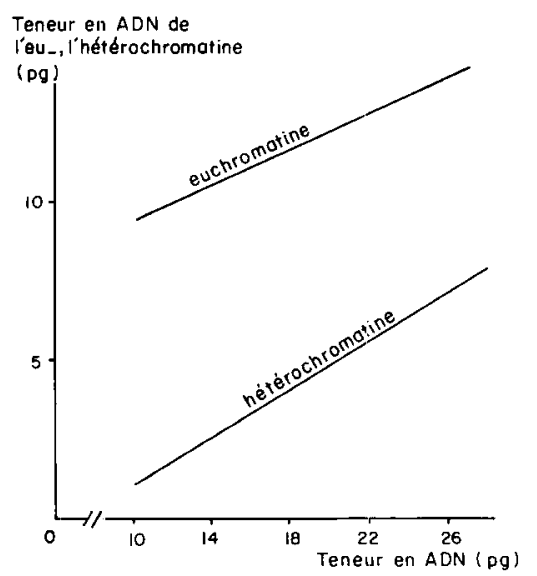

Figure 9

Relation entre la teneur en ADN total nucléaire, l'euchromatine et l'hétérochromatine (REES \& NARAYAN, 1977).

Relation between the amount of total nuclear DNA, euchromatin and heterochromatin (REES \& NARAYAN, 1977). identique. Mais les bandes non- $\mathrm{C}$ sont relativement moins condensées à la métaphase ;

3) du fait que l'on ne trouve que 32,45 p. 100 de la longueur du chromosome sous forme de bandes $\mathrm{C}$ (hétérochromatine) pour 59,5 p. 100 d'ADN répétitif, les régions hétérochromatiques pourraient être plus denses et par conséquent contenir plus d'ADN.

Il faut noter à propos du C-banding qu'il correspondrait à l'hétérochromatine constitutive, caractérisée par des séquences répétitives d'ADN et une réplication tardive.

CoMmings (1978) a étudié le mécanisme du banding et a essayé d'en déduire quels sont les composants du chromosome qui en sont responsables.

On peut espérer dans un avenir proche, avec l'extension des techniques de banding et une meilleure compréhension de leurs mécanismes, pouvoir établir une liaison plus étroite entre banding et composition en ADN. Ceci permettrait sans doute, au vu des variations obtenues dans les motifs de bandes selon les variétés, en particulier chez Lathyrus odoratus (LAVANIA \& SHARMA, 1979), d'envisager d'expliquer les variations du cycle mitotique en fonction des génotypes.

\section{CONCLUSION}

L'étude du cycle mitotique et de sa régulation peuvent apporter des informations très importantes au niveau de la connaissance de la génétique du développement.

Les facteurs physiques et chimiques sont relativement bien connus quant à leur effet sur la constance des végétaux supérieurs. Ils le sont beaucoup moins au niveau du cycle mitotique, peu d'études ayant encore été faites sur ce sujet. Cependant des observations peuvent porter sur l'effet des alternances (lumière/obscurité ou humidité/sécheresse) qui sont pratiquées empiriquement par les cytologistes pour accroître la fréquence des mitoses observées. Le seul facteur physique à avoir été largement envisagé est la température.

Pour les facteurs chimiques, des programmes de recherche devraient porter plus particulièrement sur les ions et les phytotoxines, mais il ne faudrait pas négliger cependant les substances de croissance, les préfixateurs et les nucléotides cycliques, bien que le rôle de ces derniers ne soit peut-être pas évident chez les végétaux supérieurs.

Les variations du cycle mitotique en fonction des tissus ont été démontrées dans un nombre d'espèces limité ce qui empêche de les considérer comme le cas général. On peut d'ailleurs mettre en question leur importance, étant donné que les techniques employées pour les mettre en évidence sont discutables. A l'intérieur des espèces, les variations du cycle mitotique, également peu étudiées, peuvent être envisagées d'un point de vue évolutif. Le même point de vue est à considérer pour l'effet de la polyploïdie et des chromosomes B.

Les relations $A D N$-cycle mitotique apportent quelques lueurs supplémentaires. C'est ce qui ressort des travaux mettant en évidence des relations entre fractions d'ADN et chromatine qui ont rarement été étudiées jusqu'à présent.

Les mécanismes aboutissant à la révélation des bandes chromosomiques sont encore relativement mal connus, les auteurs n'étant pas d'accord sur leur nature. Il serait intéressant de savoir si les variations de teneur en hétérochromatine, dont la corrélation très nette avec celles de l'ADN répétitif est maintenant établie, sont également liées à la diversité des bandes chromosomiques. 
Enfin on peut se demander si ces diverses caractéristiques du chromosome ont une influence sur le cycle mitotique.

Reçu le 16 septembre 1982. Accepté le 26 février 1983.

\section{REMERCIEMENTS}

Je remercic vivement MM. COMBEs et CORNu des suggestions qu'ils ont bien voulu me faire pour la rédaction de ce texte.

\section{RÉFÉRENCES BIBLIOGRAPHIQUES}

Abell C. W., Monahan T. M., 1973. The role of adenosine 3',5'cyclic monophosphate in the regulation of mammalian cell division. J. Cell Biol., 59, 549-558.

Amrhein N., 1977. The current status of cyclic AMP in higher plants. Annu. Rev. Plant Physiol., 28, 123-132.

Avanzi S., Deri P. L., 1969. Duration of mitotic cycle in two cultivars of Triticum durum as measured by ${ }^{3} \mathrm{H}$ thymidine. Caryologia, 22, 187-194.

Baetcke K. P., Sparrow A. H., Nauman C. H., Schwemmer S. S., 1967. The relationship of DNA content to nuclear and chromosome volumes and to radiosensitivity. Proc. natl. Acad. Sc. USA., 58 (1), 533-540.

Bayliss M. W., 1975. The division of cell cycle of Daucus carota L. in vivo and in vitro. Exp. Cell Res., 92, 31-38.

Bennett M. D., 1972. Nuclear DNA content and minimum generation time in herbaceous plants. Proc. R. Soc. Lond. B, 181, 109135.

Bennett M. D., Finch R. A., 1972. The mitotic cycle time of root meristem cells of Hordeum vulgare. Caryologia, 25, 439-444.

Bennett M. D., Smith J. B., 1971. The 4 C nuclear DNA content of several Hordeum genotype. Can. J. Genet. Cytol., 13, 607-611.

Berg A. R., 1966. Growth and cell division rates in the shoot apex of Chrysanthemum morifolium. Ph. D. Univ. California, Davis.

Berridge M. J., 1975a. Control of cell division : a unifying hypothesis. J. cycli. Nucleotide Res., 1 (6), 305-320.

Berridge M. J., 1975b. The interaction of cyclic nucleotides and calcium in the control of cellular activity. Adv. Cycl. Nucleotide Res., 6, 1-98.

Berridge M. J., 1976. Calcium, cyclic nucleotides and cell division. Symp. Soc. exp. Biol., 30, 219-231.

Bodson M., 1975. Variation in the rate of cell division in the apical meristem of Sinapis alba during transition to flowering. Ann. Bot., 39, 547-554.

Boyton A. L., Whitefield J. F., Isaacs R. J., 1976. The different roles of serum and calcium in the control of proliferation of BALB/c 3T3 mouse cells. In Vitro, 12, 120-123.

Bryant T. R., 1969. DNA synthesis and cell division in germinating onion. II. Mitotic cycle and DNA content. Caryologia, 22, 139-148.

Burholt D. R., Van't Hof J., 1971. Quantitative thermal induced changes in growth and cell population kinetics in Helianthus root. Am. J. Bot., 58, 386-396.

Challoner D., Simnett J. D., Hellmann K., 1981. A comparison of results obtained between two methods of detecting the existence of circadian rhythmicity in cell division : an autoradiographical and a biochemical approach. J. Cell Sci., 47, 249-265.

Choudhury H. C., 1969. Late DNA replication pattern in sex chromosomes of Melandrium. Can. J. Genet. Cytol., 11, 192-198. Clowes F. A. L., 1965. The duration of $G_{1}$ phase of mitotic cycle and its relation to radiosensitivity. New Phytol., 64, 355-359.

Clowes F. A. L., 1971. The proportion of cells that divide in root meristems of Zea mays L. Ann. Bot., 35, 240-261.

Collins G. B., 1968. DNA synthesis in two species of Nicotiana and their hybrid. J. Hered., 59, 13-17.

Commings D. E., 1978. Mechanisms of chromosome banding and implications for chromosome structure. Annu. Rev. Genet., 12, 25 46.

Corson G. E. Jr, 1969. Cell division studies in the shoot apex of Datura stramonium during transition to flowering. Am. J. Bot., 56, 1127-1134.

Dalessandro G., 1973. Interaction of auxin, cytokinin and gibberellin on cell division and xylem differentiation in cultured plants of Jerusalem artichoke. Plant Cell Physiol., 14, 1167-1176.

Das N. K., Patau K., Skoog F., 1956. Initiation of mitosis and cell division by kinetin and I.A.A. in excised tobacco pith tissue. Physiol. Plant. 9, 640-650.

Delbos M., 1979. Effet du rayonnement $\gamma$ sur des bourgeons axillaires de Nicotiana tabacum (dose - action et fractionnement de dose ) : étude cytologique. Thèse $3^{e}$ cycle, Paris XI, $38 \mathrm{p}$.

Denne M. P., 1966. Morphological changes in the shoot apex of Trifolium repens. I. Changes in the vegetative apex during the plastochron. N. Z. J. Bot., 4, 300.

Dustin A., Havas L., Lits F., 1937. Action de la colchicine sur les divisions cellulaires chez les végétaux. C.R. Assoc. Anat., 32, 170176.

Ehret C. F., Trucco E., 1967. Molecular models for circadian clock. I. The chronon concept. J. theor. Biol., 15, 240-262.

Ericksson T., 1967. Duration of the mitotic cycle in cell cultures of Haplopappus gracilis. Physiol. Plant, 20, 348-354.

Essad S., 1973. Variations du cycle mitotique et des teneurs en DNA chez Vicia sativa L. Mise en évidence de liaisons entre les durécs des phases du cycle mitotique dans différents groupes botaniques. Caryologia, 26 (3), 357.-374.

Essad S., 1976. L'organisation mitocyclique du méristème radiculaire étudiée sur Lactuca sativa. Can. J. Genet. Cytol., 18, 437-444.

Essad S., 1977. Action des températures basses sur les proportions des phases mitocycliques du méristème radiculaire de Lactuca sativa L. Physiol. veg., 15 (2), 325-332.

Essad S., 1978. L'organisation mitocyclique du méristème radiculaire de Lactuca sativa L. Il. Phénomènes pulsatoires en $G_{1}$ et conséquences sur l'interprétation de la probabilité de transition. Physiol. veg., 16 (1), 157-172.

Essad S., Bousquet J. F., 1981. Action de l'ochracine, phytotoxine de Septoria nodorum Berk., sur le cycle mitotique de Triticum aestivum L. Agronomie, 1 (8), 689-694.

Essad S., Maunoury C., 1979. Kinetic and instantaneous characteristic related to heterosis and inbreeding in Zea mays L. Ann. Amelior. Plantes, 29 (1), 689-698.

Essad S., Vallade J., Cornu A., 1975. Variations interphasiques de la teneur en DNA et des volumes nucléaires du zygote de Petunia hybrida. Conséquences métaboliques. Caryologia, 28 (2), 207-224. Evans G. M., 1968. Nuclear changes in flax. Heredity, 23, 25-38. Evans G. M., Rees H., 1971. Duration of mitotic cycle in dicotyledons and monocotyledons. Nature (G.B.), 233, 350-351.

Evans G. M., Rees H., Snell C. L., Sun S., 1972. The relationship between nuclear DNA amount and the duration of the mitotic cycle. Chromosome Today, 3, 24-31.

Evans H. J., Savage J. R. K., 1959. The effect of temperature on mitosis and the action of colchicine in root meristem cells of Vicia faba. Exp. Cell Res., 18, 51-61.

Evans H. J., Savage J. R. K., 1963. The relationship between DNA synthesis and chromosome structure as resolved by X-ray damage. J. Cell Biol., 18, 524-540.

Evans H. J., Scott D., 1964. Influence on DNA synthesis on the production of chromatid aberration by $\mathrm{X}$-rays and maleic hydrazide in Vicia faba. Genetics, 49, 17-38.

Evans H. J., Sparrow A. H., 1961. Nuclear factors affecting radiosensibility. II. Dependance on nuclear size and chromosome structure and organization. Brookhaven Symp. Biol., 14, 108-127.

Evans L. S., Van't Hof J., 1975. Dose-rate, mitotic cycle duration and sensibility of cell transitions from $G_{1} \rightarrow S$ and $G_{2} \rightarrow M$ to protracted radiation in root meristems. Rad. Res., 64, 331-343.

Falchuck K. H., Krishan A., 1977. 1,10-phenantroline inhibition of of lymphoblast cell cycle. Cancer Res., 37, 2050-2056.

Friedberg S. H., Davidson D., 1970. Duration of S phase and cell cycle in diploid and tetraploid cells of mixoploid meristems. Exp. Cell Res., 61, 216-218. 
Gelfant S., 1963. A new theory on the mechanism of cell division. Symp. int. Soc., Cell Biol., 2, 229-259.

Grant C. J., Heslot H., 1965. Remaniements chromosomiques induits par les nitrosamines chez Vicia faba et leur relation avec le cycle mitotique. Ann. Genet., 8, 98-104.

Gupta S. B., 1969. Duration of mitotic cycle and regulation of DNA replication in Nicotiana plumbaginifolia and a hybrid derivative of N. tabacum showing chromosome instability. Can. J. Genet. Cytol., 11, 133-142.

Howard A., Pelc S. R., 1953. Synthesis of desoxyribonucleic acid in normal and irradiated cells and its relation to chromosome breakage. Heredity, 6, 261-273.

Ilan J., Quastel J. H., 1966. Effect of colchicine on nucleic acid metabolism during metamorphosis of Tenebrio molitor $\mathbf{L}$. and in some mammalian tissues. Biochem. J., 100, 448-457.

Jacqmard A., 1970. Duration of the mitotic cycle in the apical bud of Rudbeckia bicolor. New Phytol., 69, 265-271.

Jona A., 1966. La durata del ciclo mitotico nelle Bellavalia romana determinata per ira autoradiografica mediante l'impiego della timidina 3 H. Caryologia, 19, 429-442.

Jouanneau J. P., 1971. Contrôle par les cytokinines de la synchronisation des mitoses dans les cellules de tabac. Exp. Cell Res., 67, 320-337.

Jouanneau J. P., 1975. Protein synthesis requirement for the cytokinin effect upon tobacco cell division. Exp. Cell Res., 71, 194197.

Kaltsikes P. J., 1972. Duration of the mitotic cycle in Triticale. Caryologia, 25, 537-542.

Kirk D., Jones R. N., 1970. Nuclear genetic activity in B chromosome rye in terms of the quantitative interrelationships between nuclear protein, nuclear RNA and histone. Chromosoma, 31, 241.

Lajtha L. G., 1963. On the concept of the cell cycle. V. Cell. comp. Physiol., 62, 143-145.

Lavania U. C., Sharma A. K., 1979. Giemsa C-banding polymorphism in Lathyrus odoratus. Nucleus, 22 (1), 34-37.

Llyod D., Poole R., Edwards S. W., 1982. The cell cycle division. Temporal organisation and control of cellular growth and reproduction. Academic Press, N.Y., 523 p.

Lyndon R. F., 1970. Rates of cell division in the shoot apical meristem of Pisum. Ann. Bot., 34, 1-17.

Mazia D., 1961. Mitosis and the physiology of cell division. In "The Cell' (ed. Brachet J., Mirsky A. E.), vol. 3, p. 77. Academic Press, N.Y.

Mc Leish J., Sunderland N., 1961. Measurements of DNA in higher plants by feulgen photometry and chemical methods. Exp. Cell Res., 24, 527-540.

Mc Leod R. D., 1968. Changes in the mitotic cycle in lateral root meristem of Vicia faba following kinetin treatment. Chromosoma, 24, 177-187.

Mc Leod R. D., 1971. The response of apical meristem of primary roots of Vicia faba to colchicine treatments. Chromosoma, 35, 217 232.

Miksche J. P., 1968. Quantitative study of intraspecific variation of DNA per cell in Ficea glauca and Pinus banksania. Can. J. Genet. Cytol., 10, 590-600.

Miksche J. P., Rollins J. A., 1971. Constancy of the duration of DNA synthesis and percent $G+C$ in white spruce from several provenances. Can. J. Genet. Cytol., 13, 415-421.

Mitchinson J. M., 1971. The biology of the cell cycle. Cambridge University Press, $313 \mathrm{p}$.

Murin A., 1966. The effect of temperature on the mitotic cycle and its time parameters in root tips of Vicia faba. Naturwissench., 53, 312-313.

Murin A., Kolekova A., 1979. The effect of high temperature on the mitotic cycle in roots of Vicia faba. Biologia (Bratislava), 34, 785791.

Murin A., Kolekova A., 1980. The effect of heat shocks on the mitotic cycle in roots of Vicia faba. Biologia (Bratislava), 35, 47-50. Nachmias U. T., Asch A., 1976. A calcium-sensitive preparation from Physarum polycephalum. Biochemistry, 15, 4273-4278.

Narayan R. K. J., Rees H., 1976. Nuclear DNA variation in Lathyrus. Chromosoma, 54 (2), 141-154.

Narayan R. K. J., Rees H., 1977. Nuclear divergence in Lathyrus species. Chromosoma, 63, 101-107.
Nishikawa K., 1970. DNA content of the individual chromosomes and genomes in wheat and its relatives. Seiken Zikô, 22, 57-65. Nougarede A., 1976. The "méristème d'attente" in Dicotyledons : behavior, origin and evolution. Symposium "Structure and function of apical meristems", XII Int. Bot. Congress (Leningrad) and Physiol. and Biochem. Cultured Plants, 8, 349-366.

Nougarede A., Rembur J., 1978. Variations of the cell cycle phases in the shoot apex of Chrysanthemum segetum L. Z. Pflanzenphysiol., 10, 1379-1389.

Pardee A. B., 1974. A restricted point for control of normal animal cell population. Proc. natl. Acad. Sci., 71, 1286-1290.

Patau K., Das N. K., Skoog F., 1957. Induction of DNA synthesis by kinetin and I.A.A. in excised tobacco pith tissue. Physiol. Plant., 10, 949-966.

Prescott D. M., 1976. The cell cycle and the control of cellular reproduction. Adv. Genet., 18, 99-177.

Quastler H., Sherman F. G., 1959. Cell population kinetics in the intestinal epithelium of the mouse. Exp. Cell Res., 17, 420-438.

Rees H., Narayan R. K. J., 1977. Evolutionary DNA-variation in Lathyrus. Chromosome Today, 6, 131-139.

Rembur J., Nougarede A., 1977. Duration of cell cycle in the shoot apex of Chrysanthemum segetum. Z. Pflanzenphysiol., 81, 173-179. Rixon R. H., Whitfield J. F., 1976. The control of liver regeneration by parathyroid hormone and calcium. J. Cell Physiol., 87, 147156.

Saint-Côme R., 1973. Détermination de la durée du cycle mitotique dans le point végétatif de Coleus blumei Benth. après traitement à la colchicine. C.R. Acad. Sci. Paris, 277, 1001-1004.

Sarma N. P., 1971. Cell cycle time and duration of $S$ phase in barley. Curr. Sci., 40, 595-596.

Seifert W. E., Rudland P. S., 1974a. Cyclic nucleotides and growth control in cultured mouse cells : correlation of changes in intracellular $3^{\prime}: 5^{\prime}{ }_{c}$ GMP concentration with a specific phase of the cell. Proc. natl. Acad. Sci., USA, 71, 4920-4924.

Seifert W. E., Rudland P. S., 1974b. Possible involvement of cyclic GMP in growth control of cultured mouse cells. Nature (Lond.), 248, $138-140$.

Sharma A. K., 1975. Chromosome banding and repeated DNA. J. Ind. Bot. Soc., 54, 1-5.

Sharma A. K., 1978. Additional genetic elements in chromosomes. Nucleus, 21 (2), 113-116.

Skoog F., Armstrong D. J., 1970. Cytokinins. Annu. Rev. Plant Physiol., 21, 359-384.

Skoog F., Leonard N. J., 1968. Sources and structures : activity relationships of cytokinins. In Wightman F., Setterfield B. Biochemistry and physiology of Plant Growth Substances. The Runge Press (Ottawa), 645 p.

Skoog F., Strong F. M., Miller C. O., 1965. Cytokinins. Science, 148, 532-533.

Skoog F., Hamazi L., Szweykowska A., Leonard N. J., Carraway K. L., Hegelson J., Loepky R. N., 1967. Cytokinins : structure/activity relationships. Phytochemistry, 6, 1169-1192.

Sluder G., 1979. Role of spindle microtubules in the control of cell cycle timing. J. Cell Biol., 80, 674-691.

Smith D. B., Flavell R. B., 1974. The relatedness and evolution of repeated nucleotide sequences in the DNA of some Gramineae species. Biochem. Genet., 12, 243-256.

Smith J. A., Martin L., 1973. Do cells cycle? Proc. natl. Acad. Sci., USA, 70, 1263-1267.

Sparrow A. H., Evans H. J., 1961. Nuclear factors affecting radiosensitivity. I. The influence of nuclear size and structure, chromosome complement and DNA content. Brookhaven Symp. Biol., 14, 76-100.

Sparrow A. H., Miksche J. P., 1961. Correlation of nuclear volume and DNA content with higher plant tolerance to chronic radiation. Science, 134, 282-283.

Sparvoli E., Gay H., Kaufmann B. P., 1966. Duration of the mitotic cycle in Haplopappus gracilis. Caryologia, 19, 65-71.

Spudich J. L., Sager R., 1980. Regulation of the Chlamydomonas cell cycle by light and dark. J. Cell Biol., 85, 136-146.

Stambrook J. P., Sachs H. G., Ebert J. D., 1975. The effect of potassium on cell membrane potential and the passage of synchronized cell through the cell cycle. J. Cell. Physiol., 85, 283-292. 
Svarinskaya R. A., Gavrilova N. S., 1976. Effect of gibberellin on the duration of mitotic cycle and on the intensity of DNA synthesis. (R. An.). Genetika, 12 (6), 30-36.

Swierienga S. H. H., Mc Manus J. R., Whitfield J. F., 1976. Regulation by calcium of the proliferation of heart cells from young adult rats. In Vitro, 12, 31-36.

Troy M. R., Wimber D. E., 1968. Evidence for a constancy of the DNA synthetic period between diploid-polyploid groups in plants. Exp. Cell Res., 53, 145-154.

Van't Hof J., 1965. Relationships between mitotic cycle duration, S period duration and the average of DNA synthesis in root meristems of several plants. Exp. Cell Res., 39, 48-58.

Van't Hof J., 1967. Studies on the relationship between cell population and growth kinetics of root meristem. Exp. Cell Res., 46, 335-347.

Van't Hof j., 1974. The duration of chromosomal DNA synthesis of the mitotic cycle and of meiosis in higher plants. In Handbook of Genetics, vol 2, pp. 363-377. R. C. King (Plenum Press).

Van't Hof J., Kovacs C. J., 1972. Mitotic regulation in the meristem of cultured roots : the principal control point hypothesis. P. 15-31, in Miller M. W. \& Kuehnert C. C. ed. The dynamics of meristem cell population, Adv. exp. med. biol., 18.

Van't Hof J., Sparrow A. H., 1963. Growth inhibition, mitotic cycle time and cell number in chronically irradiated root meristems of Pisum. Rad. Bot., 3, 239-247.

Van't Hof J., Sparrow A. H., 1965. A relationship between DNA content, nuclear volume and minimum mitotic cycle time. Proc. natl. Acad. Sci., USA, 49, 897-902.

Van't Hof J., Sparrow A. H., 1966. Comparative cell population kinetics of the tritiated thymidine labelled diploid and colchicine induced tetraploid cells in the meristem of Pisum. Exp. Cell Res., 41, 274-288

Van't Hof J., Kuniyuki A., Bjerkness C. A., 1978. The size and number of replicon families of chromosomal DNA of Arabidopsis thaliana. Chromosoma, 68, 269-285.

Verma S. C., 1978. Proximal localization of constitutive heterochromatin in the legume Lathyrus tingitanus. Nucleus, 21 (2), 125 131 .
Vosa C. G., 1973a. Heterochromatin and chromosome structure. Nobel Symposium, 23, 152-155.

Vosa C. G., 1973b. Acetic orcein, a new stain for the detection of constitutive heterochromatin in plant and animal chromosomes. Exp. Cell Res., 79, 463-465.

Vosa C. G., 1977. Heterochromatin patterns and species relationship. Nucleus, 20, 33-40.

Webster P. L., 1967. Cell cycle kinetics in meristems : effects of colchicine and 1.A.A. Ph. D. Thesis. Case Western Reserve Univ. Cleveland, Ohio.

Webster P. L., Davidson D., 1968. Evidence from thymidine ${ }^{3} \mathrm{H}$ labelled meristems of Vicia faba of two cell populations. J. Cell Biol., 39, 332-338.

Weisenberg R. C., 1972. Microtubule formation in vitro in solutions containing low calcium concentrations. Science, 177, 1104-1105.

Wightman F., Setterfield B., 1968. Biochemistry and physiology of plant growth substances. The Runge Press. Ottawa.

Wilson L., Friedkin M., 1967. The biochemical events of mitosis. II. The in vivo and in vitro binding of colchicine in grasshopper embryos and its possible relation to inhibition of mitosis. Biochemistry, 6, 3126-3135.

Wimber D. E., 1960. Duration of nuclear cycle in Tradescantia paludosa root tips as measured with ${ }^{3} \mathrm{H}$ thymidine. Am. J. Bot. 47 (10), 828-834.

Wimber D. E., 1966. Prolongation of the cell cycle in Tradescantia root by continuous irradiation. Exp. Cell Res., 42, 296-301.

Yang D. R., Dodson E. D., 1970. The amount of nuclear DNA and the duration of DNA synthesis period in related diploid and tetraploid species of oats. Chromosoma, 31, 309-320.

Zeilig C. E., Goldberg N. D., 1977. Cell cycle related changes of 3'$5^{\prime}$ cyclic GMP levels in hepatoma cells. Proc. natl. Acad. Sci., 74, 1052-1056.

Zeilig C. E., Johnson R. A., Sutherland G. W., Friedman D. L., 1976. Coordination of growth with cell division in the yeast Saccharomyces cerevisiae. J. Cell Biol., 71, 515-534.

Zeuthen E., 1964. The temperature induced division synchrony in Tetrahymena in Synchrony in cell division and growth ed. $\mathrm{E}$ Zeuthen, J. Wiley and Sons incorp., $630 \mathrm{p}$. 